\title{
СУДЕБНАЯ ПРАКТИКА
}

\section{ОСНОВНЫЕ ПОЗИЦИИ ВЕРХОВНОГО СУДА РОССИЙСКОЙ ФЕДЕРАЦИИ О ПОРУЧИТЕЛЬСТВЕ (ПО ПОСТАНОВЛЕНИЮ ПЛЕНУМА ВЕРХОВНОГО СУДА РОССИЙСКОЙ ФЕДЕРАЦИИ «О НЕКОТОРЫХ ВОПРОСАХ РАЗРЕШЕНИЯ СПОРОВ О ПОРУЧИТЕЛЬСТВЕ» ОТ 24 ДЕКАБРЯ 2020 ГОДА № 45)}

\author{
Ломидзе \\ Ольга \\ Георгиевна \\ Ломидзе \\ Эдуард \\ Юрьевич
}

доктор юридических наук, профессор кафедры гражданского и предпринимательского права, Южно-Российский институт управления - филиал Российской академии народного хозяйства и государственной службы при Президенте РФ (344002, Россия, г. Ростов-на-Дону, ул. Пушкинская, 70/54). кандидат юридических наук, доцент кафедры гражданского и предпринимательского права, Южно-Российский институт управления - филиал Российской академии народного хозяйства и государственной службы при Президенте РФ (344002, Россия, г. Ростов-на-Дону, ул. Пушкинская, 70/54). E-mail: pismabudut@yandex.ru

\begin{abstract}
Аннотация
В статье анализируются основные позиции Верховного Суда Российской Федерации по договору поручительства с учетом последнего акта легального толкования по данному вопросу. В статье обсуждается правовая природа поручительства и корректировка судебной практики в связи с изменением правового регулирования договора поручительства. В статье предлагается вариант решения спора в ситуации, когда поручитель заранее дал согласие отвечать перед кредитором при переводе на другое лицо долга по основному обязательству.

Ключевые слова: регулирование поручительства, виды поручительства, исполнение обязательства, срок поручительства, досрочное исполнение, акт легального толкования, гражданское законодательство, согласие на совершение сделки, отзыв акцепта.
\end{abstract}

24 декабря 2020 года Пленум Верховного Суда Российской Федерации принял постановление «0 некоторых вопросах разрешения споров о поручительстве» № 45 (далее - Пленум № 45, Пленум). Воспринимая по ряду вопросов позиции, выраженные в постановлении Пленума Высшего Арбитражного Суда Российской Федерации от 12 июля 2012 года № 42 «0 некоторых вопросах разрешения споров, связанных с поручительством», Пленум № 45 продвигает интерпретацию положений о поручительстве на новый уровень. Структура постановления Пленума позволяет обеспечить достаточный объем разъяснений для единообразного применения судами положений Гражданского кодекса Российской Федерации о поручительстве.

В настоящей статье мы отметим несколько наиболее на наш взгляд важных подходов и удачных решений, получивших отражение в Пленуме.

\section{1. Правовая природа поручительства}

Основной вопрос, влияющий на регулирование поручительства и толкование всех положений § 5 главы 23 Гражданского кодекса Российской Федерации (далее также Кодекс) о правовой природе поручительства, а именно о том, принимает ли поручитель на себя самостоятельное обязательство перед кредитором либо он становится «содолжником» в обеспечиваемом обязательстве. От его решения зависят, среди прочего, пределы признаваемой свободы соответствующего договора. 
В Пленуме № 45 получил отражение подход, согласно которому поручитель принимает на себя самостоятельное обязательство перед кредитором, поручитель не является должником в основном (обеспеченном поручительством) обязательстве.

Опираясь именно на этот общий подход, в Пленуме № 45 признаны:

- возможность обеспечения обязанностей поручителя перед кредитором (неустойкой, залогом, поручительством, независимой гарантией и др.) - пункты 1, 18 Пленума;

- возможность обеспечения поручительством неденежного обязательства - пункт 2 Пленума (обязанность поручителя исполняется им в денежной форме);

- возможность обеспечения поручительством внедоговорных обязательств, в том числе возникших из деликтов, и тех, которые возникнут в будущем - пункт 3 Пленума;

- возможность заключения договора поручительства под отменительным или отлагательным условием (статья 157 Кодекса, пункт 8 Пленума).

Самостоятельность обязательства поручителя перед кредитором объясняет отсутствие необходимости получения согласия должника для заключения договора поручительства и даже уведомления должника о заключении такого договора (пункт 4 Пленума). Возможные злоупотребления (недобросовестные согласованные действия кредитора и поручителя, направленные на заключение договора поручительства исключительно с целью изменения его подсудности), если о них будет своевременно заявлено (до представления первого заявления ответчика по существу спора в суде первой инстанции) и они будут доказаны, преодолеваются посредством игнорирования договора поручительства при определении подсудности спора (пункт 52 Пленума № 45).

Данная характеристика объясняет суброгацию. Она же влияет на решение вопроса о возражениях, которые поручитель вправе заявлять против требований кредитора. В пункте 17 Пленума разъяснено, что наряду с возражениями, которые возникают в отношениях кредитора и должника, поручитель вправе заявлять возражения, основанные на его отношениях с кредитором. Также разъяснено, что условия договора поручительства, ограничивающие такие возражения, ничтожны (со ссылкой на пункт 1 статьи 361 и пункт 2 статьи 168 Кодекса).

Рассматриваемая характеристика обязательства влияет на решение Кодексом и Пленумом № 45 вопроса об объеме ответственности поручителя наследодателя после открытия наследства. Пленум признает неподлежащим применению пункт 62 постановления Пленума Верховного Суда Российской Федерации от 29 мая 2012 года № 9 «О судебной практике по делам о наследовании». Тем самым устраняет из интерпретационного акта Верховного Суда Российской Федерации разъяснение, не соответствующее действующему правовому регулированию ${ }^{1}$.

Договор поручительства - это соглашение поручителя и кредитора, он не зависит (если в нем не указано иное) от отношений поручителя и должника, что получило отражение в пункте 29 Пленума.

Поручительство - это акцессорное обязательство, зависит от судьбы основного: прекращается по общему правилу при прекращении основного обязательства (пункт 30 Пленума № 45). При этом Пленум № 45 обращает внимание на то, что действие поручительства не находится в прямой зависимости от действия договора между должником и кредитором, поскольку расторжение договора вовсе не означает прекращение возникшей из него правовой связи сторон - пункт 31 Пленума.

\footnotetext{
${ }^{1}$ Напомним, что Федеральным законом от 08 марта 2015 года № 42-Ф3 внесены изменения в положения пункта 3 статьи 364 и пункта 4 статьи 367 Гражданского кодекса Российской Федерации. Изменения вступили в силу с 1 июня 2015 года. Данными изменениями нивелированы расхождения в толкованиях, которые были даны ранее Верховным судом Российской Федерации и Высшим Арбитражным Судом Российской Федерации, по вопросу о необходимости согласия поручителя отвечать за наследников должника и по вопросу об объеме ответственности поручителя в случае смерти должника (пункт 20 постановления Пленума Высшего Арбитражного Суда Российской Федерации от 12 июля 2012 года №42 «0 некоторых вопросах разрешения споров, связанных с поручительством», пункт 62 постановления Пленума Верховного Суда Российской Федерации от 29 мая 2012 года №9 «0 судебной практики по делам о наследовании»). Позиция, изложенная в пункте 62 постановление Пленума Верховного Суда Российской Федерации от 29 мая 2012 года №9, была также продублирована в пункте 9 Обзора ВС РФ от 22.05.2013.
} 


\section{2. Виды поручительства}

Пленум № 45 в пунктах 11-15 закрепляет следующие основные классификации поручительства:

- поручительство с солидарной ответственностью поручителя и должника и субсидиарной ответственностью поручителя за должника (основание деления - характер обязательства поручителя), по умолчанию, если сторонами не согласовано иного, ответственность солидарная;

- поручительство одного лица и поручительство нескольких лиц (классификация по количеству поручителей);

- для поручительства нескольких лиц: совместное (сопоручительство) и раздельное поручительство (классификация по критерию наличия множественности в обязательстве на стороне поручителя);

- для сопоручительства: сопоручительство с солидарной обязанностью (ответственностью) сопоручителей и сопоручительство с ограничением ответственности каждого сопоручителя перед кредитором (когда каждый по общему правилу отвечает в своей части) по характеру обязательства.

При раздельном поручительстве каждый поручитель отвечает сам за себя, в рамках своего обязательства, кредитор при этом по общему правилу может предъявить свои требования к любому. При исполнении одним из таких поручителей обязательства задолжника к нему в порядке суброгации переходят права кредитора, в том числе основанные на других поручительствах.

Сопоручители реализуют волю совместно претерпевать последствия неисполнения основного обязательства должником, распределить эти последствия между собой (наблюдаем множественность в обязательстве поручительства на стороне поручителя). В отличие от раздельного поручительства последствием исполнения одним из сопоручителей обязательства должника является по общему правилу регресс (т.е. сопоручитель, исполнивший обязательство, имеет право регрессного требования к остальным сопоручителям в равных долях, за вычетом доли, подающей на него самого). Указание на регресс в рассматриваемой ситуации является следствием наличия специальной нормы подпункта 1 пункта 2 статьи 325 Гражданского кодекса Российской Федерации, которой корреспондирует пункт 3 статьи 363 Кодекса.

Квалификация поручительства как совместного или раздельного может вызывать затруднения. Между тем от нее зависят практически важные последствия. В частности, возможность солидарного взыскания с поручителей задолженности, последствия исполнения поручителем обязанности (суброгация или регресс), течение срока исковой давности (статья 201 Кодекса или пункт 3 статьи 200 Кодекса). Пленум № 45 указывает следующий ориентир: при отсутствии четких условий договора, свидетельствующих о совместном поручительстве, о таком характере поручительства (пока не доказано иное) свидетельствует заключение договора с аффилированными лицами.

К сопоручителям применяются правила подпункта 1 пункта 2 статьи 325 Гражданского кодекса Российской Федерации, в том числе при банкротстве одного из них.

В Пленуме дано разъяснение, согласно которому правило о совместном поручительстве применяется также при совместной выдаче обеспечения поручителем залогодателем, не являющимся должником по обязательству - пункт 15 Пленума № 45.

\section{3. Последствия исполнения поручителем обязательства кредитору}

Общее последствие исполнения поручителем обязательства - суброгация, которая является разновидностью перехода прав и обязанностей на основании закона (статья 387 Кодекса).

Отметим весьма важную интерпретацию пункта 1 статьи 365 Кодекса, которая получила отражение в пункте 18 Пленума № 45.

Согласно пункту 1 статьи 365 Кодекса к поручителю, исполнившему обязательство, переходят права кредитора по этому обязательству и права, принадлежавшие кредитору как залогодержателю, в том объеме, в котором поручитель удовлетворил требование кредитора. Поручитель также вправе (выделено нами) требовать от должника уплаты процентов 
на сумму, выплаченную кредитору, и возмещения иных убытков, понесенных в связи с ответственностью за должника.

Пункт 18 Пленума № 45 повторяет указание Кодекса на суброгацию в качестве общего правила, и далее разъясняет: вместо суммы, определенной в порядке суброгации, поручитель вправе потребовать от должника сумму фактически уплаченного кредитору, а также проценты на основании статьи 395 Кодекса, начисленные на эту сумму. Уточнено, что это толкование относится ко второму предложению пункта 1 статьи 365 Кодекса.

Пленум поясняет, что и в первом, и во втором случаях речь идет о переходе прав кредитора к поручителю, исполнившему обязательство перед кредитором. Это не влияет на течение срока исковой давности по требованиям к должнику (статья 201 ГК РФ).

Кодекс содержит положение, призванное не допустить «двойное» исполнение обязательства перед кредитором, т.е. и должником, и поручителем. Пункт 2 статьи 366 Кодекса возлагает на должника, исполнившего обязательство, обеспеченное поручительством, обязанность известить об этом поручителя немедленно. При нарушении должником этого правила, следствием которого явится исполнение поручителем (наряду с должником) обязательства перед кредитором, поручителю предоставлен выбор: взыскать с кредитора неосновательно полученное или предъявить регрессное требование к должнику. При этом установлены последствия реализации поручителем своих требований к должнику: должник в этом случае вправе взыскать с кредитора лишь неосновательно полученное.

Т.е. Кодекс вводит негативные последствия для должника, не предпринявшего мер для исключения двойного исполнения, если оно произошло.

Пленум дает разъяснение, корректирующее данное негативное последствие для ситуации, в которой такое двойное исполнение произошло по причинам, зависящим также и от кредитора. Согласно пункту 22 Пленума если кредитор умышленно совершил действия, направленные на получение удовлетворения от поручителя, несмотря на то, что обязательство прекратилось исполнением должника, последний также вправе потребовать возмещения и иных убытков (пункт 4 статьи 1, пункт 2 статьи 366 и пункт 4 статьи 401 Кодекса).

\section{4. Корректировка толкования в связи с изменением правового регулирования}

Поручительством достаточно часто обеспечиваются заемные и кредитные обязательства. Одним из востребованных способов защиты нарушенного заемщиком права кредитора в этих обязательствах является предъявление кредитором требования о досрочном возврате суммы займа.

Реализация заемшиком возможностей, установленных пунктом 2 статьи 811 Кодекса в виде предъявления кредитором требования о досрочном возврате суммы займа (кредита) изменяет срок исполнения обязательства по возврату суммы долга (кредита). В том числе для ситуации согласования с заемщиком графика аннуитетных платежей.

Предъявление требования о досрочном исполнении обязательства кредитором является действием кредитора по защите своего права. Но влияет ли это на его отношения с поручителем? Вправе ли кредитор предъявить требование не только к должнику, но и к поручителю, исходя из акцессорного характера поручительства?

Данный вопрос сопряжен с иным, не менее актуальным, а именно с вопросом о правилах исчисления годичного срока для ситуации, в которой кредитор вправе предъявить свое требование досрочно, при этом срок поручительства в договоре поручительства не установлен (абзац первый пункта 6 статьи 367 Гражданского кодекса Российской Федерации).

Напомним, что пункт 34 постановления Пленума Высшего Арбитражного суда Российской Федерации от 12 июля 2012 года № 42 «0 некоторых вопросах разрешения споров, связанных с поручительством» содержал следующее разъяснение по отмеченному вопросу: «В случае если у кредитора, требования которого обеспечены поручительством, не содержащим условие о сроке его действия, возникло право потребовать досрочного исполнения обязательства (например, в соответствии с пунктом 2 статьи 811 ГК РФ), годичный срок для предъявления требования к поручителю исчисляется со дня, когда кредитор предъявил к должнику требование о досрочном исполнении обязательства, если только иной срок или порядок его определения не установлен договором поручительства». 
Схожее разъяснение содержал Обзор судебной практики Верховного Суда Российской Федерации № 2, утвержденный Президиумом Верховного Суда Российской Федерации 26 июня 2015 года.

Между тем Пленум Высшего Арбитражного суда Российской Федерации от 12 июля 2012 года № 42 был принят до внесения изменений в положения Кодекса о поручительстве Федеральным законом от 08 марта 2015 года № 42-Ф3.

Пункт 2 статьи 367 Кодекса в редакции указанного Федерального закона устанавливает следующее правило относительно последствий изменения обеспеченного поручительством обязательства без согласия поручителя: если такое изменение влечет увеличение ответственности или иные неблагоприятные последствия для поручителя, то поручитель отвечает на прежних условиях.

В качестве одного из неблагоприятных для поручителя последствий изменения обеспеченного поручительством обязательства Пленум № 45 рассматривает уменьшение срока исполнения основного обязательства.

Со ссылкой на положение пункта 2 статьи 367 Кодекса в пункте 24 Пленума, посвященном последствиям несогласованного с поручителем увеличения или уменьшения срока исполнения основного обязательства, закреплено толкование, согласно которому «в случае уменьшения срока исполнения основного обязательства без согласия поручителя кредитор вправе требовать от поручителя исполнения его обязанности после истечения срока основного обязательства, который был установлен первоначально» (абзац второй пункта 24 Пленума № 45).

При внешней видимости поддержки интересов поручителя данное толкование вряд ли можно отнести к «пропоручительским». Оно по своей сути «прокредиторское».

Разъяснение соответствует общему подходу о самостоятельности обязательства поручителя. Однако с практической толчки зрения, очевидно, что поручитель, как правило, принимает на себя соответствующие обязательства по просьбе должника, будучи так или иначе с ним связанным, в том числе возмездным договором. Должник, при предъявлении к нему требования досрочно со ссылкой на пункт 2 статьи 811 Кодекса, будет рассчитывать, в том числе, и на поручителя.

Поручитель, в свою очередь, всегда заинтересован в максимальном сокращении срока действия своего обязательства. Т.е. в исчислении годичного срока для ситуации, в которой срок поручительства в договоре поручительства не установлен (абзац первый пункта 6 статьи 367 Гражданского кодекса Российской Федерации), с более ранней даты.

По сути, реализация требования о досрочном исполнении в порядке пункта 2 статьи 811 Кодекса не способна сократить годичный срок действия поручительства, однако в ситуации, когда этот срок не установлен договором, способна повлиять на даты его начала и окончания.

Между тем воспретив кредитору досрочно обращаться к поручителю, в том числе при реализации им права согласно пункту 2 статьи 811 Кодекса, было бы очевидной ошибкой обусловить срок действия поручительства новым (сокращенным) сроком исполнения своего обязательства должником. Ведь при таком подходе пресекательный срок действий поручительства может быть исчерпан до того момента, когда кредитор будет вправе предъявить требования к поручителю в соответствии с первоначально согласованными условиями основного обязательства.

В пункте 44 Пленума № 45 со ссылкой на пункт 6 статьи 367 Кодекса закреплено следующее токование: «предъявление кредитором к должнику требования о досрочном исполнении основного обязательства, в том числе когда срок исполнения в силу закона считается наступившим ранее, чем предусмотрено условиями этого обязательства, не сокращает срок действия поручительства, определяемый исходя из первоначальных условий основного обязательства. В этом случае срок действия поручительства исчисляется исходя из первоначальных условий основного обязательства, как если бы не было предъявлено требование о досрочном исполнении обязательства».

Предъявление кредитором к должнику требования о досрочном исполнении обязательства согласно абзацу второму пункта 6 статьи 367 Кодекса не сокращает срок действия поручительства, определяемый исходя из первоначальных условий основного обязательства. 
Однако, как отмечено выше, реализация требования о досрочном исполнении в порядке пункта 2 статьи 811 Кодекса не способна сократить годичный срок действия поручительства. Она может лишь повлиять на даты его начала и окончания (при отсутствии условия о сроке в договоре).

Толкование Пленума № 45 для ситуаций несогласованного с поручителем досрочного предъявления кредитором своего требования к должнику в порядке пункта 2 статьи 811 Кодекса «разрывает» срок действия поручительства с наступлением срока исполнения обеспеченного поручительством обязательства.

Положения пунктов 24 и 44 Пленума № 45 исходят из того, что уменьшение срока исполнения основного обязательства без согласия поручителя ни при каких условиях не влияет на отношения кредитора и поручителя, в том числе в ситуации возникновения у кредитора права на досрочное исполнение.

В основе этого толкования - оценка такого изменения как неблагоприятного для поручителя.

\section{5. Вопрос, который остался нерешенным}

В пункте 27 Пленума № 45 дано толкование, допускающее ситуацию, в которой поручитель заранее дает свое согласие отвечать перед кредитором при переводе на другое лицо долга по основному обязательству.

Заблаговременность согласия обусловливает проблему его отзыва поручителем. Предъявление поручителем соответствующего довода при рассмотрении судом дела по иску кредитора к поручителю потребует от суда оценки последствий такого отзыва. Особенно если оно будет совершено до направления поручителю уведомления о переводе долга на нового должника.

Пленум № 45 разъяснения по обозначенному вопросу не содержит. Доктрине и практике предстоит выработать подход к решению этого вопроса.

Разъяснение последствий отзыва заранее данного согласия поручителя осложняется отсутствием в гражданском законодательстве регулирования отзыва юридически значимых согласий.

Отметим два подхода Верховного Суда Российской Федерации.

1. Разъяснение, которое дано Верховным Судом Российской Федерации по вопросу о возможности отзыва согласия третьего лица на совершение сделки в пункте 57 постановления Пленума Верховного Суда Российской Федерации от 23 июня 2015 № 25 «0 применении судами некоторых положений раздела I части первой Гражданского кодекса Российской Федерации».

Согласно указанному толкованию третье лицо, давшее предварительное согласие на совершение сделки, вправе отозвать его, уведомив стороны сделки до момента ее совершения и возместив им убытки, вызванные таким отзывом. По аналогии закона применены положения об отзыве акцепта (пункт 1 статьи 6, статья 439 Кодекса).

Этот подход может быть принят, если рассматривать согласие поручителя только как предварительное согласие на совершение сделки.

2. Положения пункта 26 Обзора судебной практики Верховного Суда Российской Федерации № 2 (2018), утвержденного Президиумом Верховного Суда Российской Федерации 04 июля 2018 года.

Этот подход основан на недопустимости (по общему правилу) изменения договора в одностороннем порядке (пункт 1 статьи 450 Гражданского кодекса Российской Федерации).

Рассматриваемое толкование посвящено вопросу о возможности отзыва арендодателем в одностороннем порядке согласия арендодателя на сдачу имущества в субаренду.

Разъяснено, что по общему правилу, если иное не предусмотрено договором аренды, согласие арендодателя на сдачу имущества в субаренду, закрепленное сторонами в качестве условия договора при его заключении, не может быть отозвано арендодателем в одностороннем порядке без внесения изменений в договор по правилам гражданского законодательства.

Такое условие договора аренды может быть изменено только по правилам, предусмотренным гражданским законодательством (пункт 1 статьи 310, пункт 1 статьи 450 Кодекса). 
Согласованное сторонами договора условие о праве арендатора сдавать арендованное имущество в субаренду согласно данному толкованию не является предварительным согласием на совершение сделки по смыслу пункта 3 статьи 157.1 Кодекса, которое вправе отозвать давшее его лицо.

Этот подход может быть принят, если рассматривать согласие поручителя отвечать за нового должника в качестве условия договора поручительства.

Lomidze Olga Georgievna, Doctor of Law, Professor, Department of Civil and Business Law, SouthRussian Institute of Management - branch of Russian Presidential Academy of National Economy and Public Administration (70/54, Pushkinskaya St., Rostov-on-Don, 344002, Russian Federation).

Lomidze Eduard Yuryevich, Candidate of Law, Associate Professor, Department of Civil and Business Law, South-Russian Institute of Management - branch of Russian Presidential Academy of National Economy and Public Administration (70/54, Pushkinskaya St., Rostov-on-Don, 344002, Russian Federation). E-mail: pismabudut@yandex.ru

\title{
THE MAIN POSITIONS OF THE SUPREME COURT OF THE RUSSIAN FEDERATION ON SURETY (ACCORDING TO THE RESOLUTION OF THE PLENUM OF THE SUPREME COURT OF THE RUSSIAN FEDERATION "ON SOME ISSUES OF RESOLVING DISPUTES ABOUT SURETY" DATED DECEMBER 24, 2020 № 45)
}

\begin{abstract}
The article analyzes the main positions of the Supreme Court of the Russian Federation on the surety agreement, taking into account the latest act of legal interpretation on this issue. The article discusses the legal nature of the surety and the adjustment of judicial practice in connection with the change in the legal regulation of the surety agreement. The article proposes a variant of resolving a dispute in a situation where the guarantor agreed in advance to answer to the creditor when transferring the debt under the main obligation to another person.

Keywords: regulation of surety, types of surety, performance of an obligation, term of surety, early performance, act of legal interpretation, civil legislation, consent to a transaction, withdrawal of acceptance.
\end{abstract}

